\title{
Constituent frequency effects in the written production of Spanish compound words
}

\author{
Olivia Afonso $^{1}$ (D) Carlos J. Álvarez ${ }^{2}$
}

Published online: 18 April 2019

(C) The Psychonomic Society, Inc. 2019

\begin{abstract}
The debate about whether compound words are accessed as whole words or via their constituents remains unresolved, especially in the field of language production. In this study, three experiments used a copying task to examine whether compound words are accessed via their constituents in handwriting production. In Experiment 1, production of compound words and noncompounds was compared. The last interletter interval within the first constituent of compounds was observed to be shorter than the same interval in noncompounds, revealing that writing durations are sensitive to morphological processing. In Experiments 2 and 3 , the first and second constituent frequency was manipulated respectively. The frequency of both constituents affected writing onset times. Interestingly, the interval between the last two letters of the first constituent was shorter when the second constituent was of high frequency, suggesting that the effect obtained in this position in Experiment 1 was related to the anticipation of the second constituent. Our findings indicate that both constituents are activated before the initiation of the written response and that the second component is reactivated before the production of the first constituent has finished.
\end{abstract}

Keywords Compound words $\cdot$ Writing onset time $\cdot$ Writing durations $\cdot$ Morphology $\cdot$ Language production

Compounds are a specific type of morphologically complex words in which two or more lexemes are included (VergaraMartínez, Duñabeitia, Laka, \& Carreiras, 2009). The issue of how compound words are processed has been of particular interest in language comprehension and spoken production research because of its relevance for theories of morphological processing. According to the so-called full-form representation hypothesis, a compound word (e.g., birthday) would be processed as a whole-word form, just as a monomorphemic word. Conversely, from the point of view of the decomposition hypothesis (Duñabeitia, Perea, \& Carreiras, 2007; Fiorentino \& Poeppel, 2007; Pollatsek, Hyönä, \& Bertram,

Olivia Afonso

afonso.o@brookes.ac.uk

Carlos J. Álvarez

calvarez@ull.es

1 Department of Psychology, Health, \& Professional Development, Oxford Brookes University, Gipsy Lane, Headington, Oxfordshire 0X3 0BP, UK

2 Departamento de Psicología Cognitiva, Social y Organizacional, Universidad de La Laguna, Campus de Guajara, 38200 San Cristóbal de La Laguna, Tenerife, Spain
2000), compounds would be accessed via their constituent lexemes (birth and day). It has been also proposed that processing compound words may rely on two different routes: one based on the whole-word form and another based on morphological decomposition (Caramazza, Laudanna, \& Romani, 1988; Schreuder \& Baayen, 1997). The relative impact of each route would depend on certain characteristics of the task (Janssen, Pajtas, \& Caramazza, 2014), such as the type of stimulus used to elicit the response. According to this point of view, stimuli transparently including the constituent lexemes (i.e., if words were presented visually or aurally) would lead to morphological decomposition, while the name of a picture would be accessed as a whole word. In this study, we investigate the nature and time course of the morphological processing of compound words in written production.

In language-comprehension research, it is widely agreed that compound words are accessed via their constituents (Duñabeitia et al., 2007; Janssen et al., 2014; Juhasz, Starr, Inhoff, \& Placke, 2003; Vergara-Martínez et al., 2009). Most of the evidence supporting this claim has come from studies comparing the effects produced by the frequency of the compound and the frequency of the constituents on reaction times. Effects of constituent frequency are interpreted as being indicative of morphological decomposition, whereas effects of 
whole-word frequency are considered to reflect holistic processing of the compound. The frequency of the constituents often have been reported to affect reaction times in lexical decision (Duñabeitia et al., 2007; Janssen et al., 2014; Juhasz et al., 2003) and reading tasks (Juhasz et al., 2003; Pollatsek et al., 2000), suggesting that compound words are morphologically decomposed during these tasks. For example, Duñabeitia et al. (2007) obtained significant effects of the frequency of the second constituent in lexical decision both in Spanish and Basque, despite the important differences between these languages' morphologies (e.g., the level of morpheme agglutination allowed).

Less clear is whether or not compounds are accessed via their constituents in language production. Although effects of the frequency of the first or second constituent have been observed in several studies using spoken production tasks (Bien, Levelt, \& Baayen, 2005), some findings strongly support the idea that compounds are retrieved as whole-word forms (Bertram, Tønnessen, Strömqvist, Hyönä, \& Niemi, 2015; Janssen, Bi, \& Caramazza, 2008). In a study conducted in English and Chinese, Janssen et al. (2008) observed that naming latencies in a picture-naming task were sensitive to the compounds' surface frequency (or whole-word frequency), but not to the frequency of the first or second constituents. These findings were confirmed by Janssen et al. (2014) in another study conducted with English speakers. Interestingly, these authors also carried out an analysis on the lexical decision times available in the English Lexicon Project (Balota et al., 2007). In this case, latencies were found to be sensitive to the compound's surface frequency, but also to the first and second constituent frequency. Janssen and colleagues proposed that this pattern of results, together with previous findings obtained in language comprehension, could be accounted for by a dualroute system that is affected by the characteristics of the task. Specifically, they claimed that the use of a whole-word form route or a route based on morphological decomposition would depend on whether or not the compound's constituents are transparently contained in the input used in the task. Thus, effects consistent with a decomposition procedure would be observed in language comprehension studies, where the constituents are unavoidably included in the input (whether this is a visual or acoustic representation of the compound word). The same would apply to production studies in which the constituents are somewhat presented to the participants. This could be a picture-word interference task or any paradigm in which participants are exposed to the compound word, and thus to its constituents. However, in a task such as picture naming, the full form of the compound would be accessed, and no effects of the characteristics of the constituents should be found. This explanation seems to fit the findings reported in a wide range of spoken production tasks. For example, studies using priming paradigms or picture-word interference have usually obtained evidence supporting that compounds are accessed via their constituents (Dohmes, Zwitserlood, \& Bölte, 2004; Koester \& Schiller, 2008). In picture-naming tasks, though, response latencies seem to be explained only by the frequency of the compound word (Cohen-Goldberg, 2013; Janssen et al., 2008; Janssen et al., 2014).

To our knowledge, there is only one study that has investigated this issue in written production. Bertram et al. (2015) asked Finnish participants to perform a typewritten picturenaming task in which picture names were compound words varying in the frequency of the constituents and in wholeword frequency. Results revealed that writing onset times were sensitive to the compound frequency, but not to the frequency of the first or the second constituent. This finding could be interpreted as evidence of compounds being accessed as whole words in writing tasks. However, Bertram and colleagues suggested that, given the pervasiveness of the constituent frequency effects in language comprehension research, their findings might be better integrated by the dual-route system proposed by Janssen et al. (2014). Thus, they predicted that constituent frequency effects would be observed in a writing task in which the constituents were transparently included in the input, such as a word-copying task. If constituent frequency can be obtained in certain writing tasks, written production research could provide a unique opportunity to investigate to what extent all the constituents of a compound are planned before the response is initiated. This question may be addressed more easily in written than in spoken production because writing not only takes longer to be produced but it is also less practised than speaking. This fact may leave more scope for high-level processes to affect motor processes in handwriting (Delattre, Bonin, \& Barry, 2006).

Assuming that morphological decomposition may occur during compound word written production, it still remains unclear how and when each constituent would be retrieved. It is possible that both constituents must be planned before the motor modules are engaged in order to emit a response. However, it may also be the case that only the first constituent needs to be planned in order to initiate the response, while the second constituent could be planned during the production of the first constituent. Because handwritten production is a slow process compared with spoken production, it is possible to measure the duration of a written response and even the duration of a specific segment of the response. In recent years, evidence has indicated that writing durations are sensitive to different types of linguistic variables (Afonso, Álvarez, \& Kandel, 2015; Álvarez, Cottrell, \& Afonso, 2009; Kandel, Peereman, \& Ghimenton, 2014; Kandel \& Perret, 2015; Roux, McKeeff, Grosjacques, Afonso, \& Kandel, 2013), including morphological variables (Kandel, Álvarez, \& Vallée, 2008; Kandel, Spinelli, Tremblay, Guerassimovitch, \& Álvarez, 2012). Kandel et al. (2008) reported that an interletter interval (henceforth, ILI) was longer if it preceded a suffix (e.g., in boul_ette) than when the same sequence of letters 
was not a suffix (e.g., in goél_ette). These findings seem to confirm that linguistic (central) levels of processing are not necessarily finished when motor (peripheral) processes start. Moreover, they indicate that some kind of morphological decomposition may take place during writing production. Thus, by measuring writing onset times and writing durations, it may be possible to establish whether both constituents are fully planned before writing starts or, on the contrary, if the second constituent is retrieved during the actual production of the response. In their typewriting study, Bertram et al. (2015) observed no pattern of results supporting a decomposition account in writing onset times, but they did obtain some evidence of morphological processing in the duration of the interkey intervals (henceforth, IKI). Specifically, they observed longer IKI durations for intervals that represented a morpheme boundary than for intervals that did not represent a morpheme boundary. The authors interpreted this finding as evidence of the impact of morphology on written production, although it was unclear from their results if this effect was related to the late processing of the first constituent or the anticipation of the second constituent.

In this study, we report three experiments using a copying task designed to gain information about these issues. This series of experiments were set out to determine whether or not compound words are accessed via their constituents during a copying task, as predicted by a dual-route procedure such as that proposed by Janssen et al. (2014). In Experiment 1, compound words were compared with noncompound words to elucidate whether or not handwritten production is affected by morphological complexity. In Experiment 2, the frequency of the first constituent of compound words was manipulated, and both the whole-word frequency and the second constituent frequency were kept constant. In Experiment 3, the frequency of the second constituent was manipulated while the frequency of the first constituent and the compound frequency were kept constant. Both writing onset times and ILIs were measured to explore when the different constituents are planned for production. If an effect of morphological decomposition is actually observed in online writing measures, then the manipulation of the frequency of each constituent may provide information about whether this effect is related to the processing of the first or the second constituent.

\section{Experiment 1}

\section{Method}

Participants Thirty-two students ( 24 females), between 18 and 28 years of age ( $M=19$ years and 3 months; $S D=1$ year and 7 months), from introductory courses of the University of La Laguna, took part in this experiment to fulfil a course credit requirement. All of them were native Spanish speakers with no known motor or perceptive disorders. Before the study, all participants read and signed an informed consent form in accordance with the Declaration of Helsinki.

Materials Forty Spanish words were selected as experimental stimuli. Twenty were compounds (e.g., TOCA.DISCOS, record player; henceforth, the dot represents the position of the morpheme boundary) and 20 were noncompounds (PESADUMBRE, sorrow). Although a number of noncompound words were morphologically complex, none of these words could be segmented into two strings of letters, both of them with lexical status. Across conditions, words were matched by the identity of the bigram located at the position corresponding to the morpheme boundary in compounds and the equivalent position in noncompounds (TOCA.DISCOS, PESADUMBRE respectively). In none of the noncompounds did this position represent a morphological boundary. Moreover, word frequency, word length (in number of letters and syllables), orthographic neighbourhood, mean bigram frequency, and the frequency of the bigram previous to the morpheme boundary (i.e., TOC_A.DISCOS) were controlled for (all $t s<2$ ) according to the values provided by EsPal (Duchon, Perea, Sebastián-Gallés, Martí, \& Carreiras, 2013), a Web repository of Spanish words based on a 300 million token written database. The full list of materials used in Experiment 1 and the values for these controlled variables are shown in Appendix Table 4.

Apparatus Stimulus presentation and the recording of the written response were controlled by Ductus (Guinet \& Kandel, 2010). The experiment was run on an Asus F9Eseries laptop. A WACOM Intuos 5 graphic tablet connected to the laptop and an Intuos Inking Pen (ink removed) were used to register the participants' responses.

Procedure Participants were asked to perform a copying task. Each trial started with a 500-ms fixation point (+) in the centre of the screen, which was immediately followed by the presentation of a centred word (written in 16-point lowercase Times New Roman font) that disappeared after 500 ms. This procedure was chosen to avoid participants reading the stimulus during writing production. This ensured that any potential effect obtained in writing durations could be attributed to production processes rather than to reading processes. Participants had to write the word in uppercase (print handwriting was not enforced) on a line draw in a sheet of paper placed over the graphic tablet as quickly and accurately as possible. They were instructed to tap with the tip of the pen a square located at the bottom right of the response sheet to initiate the next trial and then quickly place the pen over the response line without making any contact with the paper. The experiment was conducted individually in a soundproof room and lasted approximately $15 \mathrm{~min}$. 
Statistical analyses Writing onset times, the duration of the critical letters, and the duration of the intervals previous to these letters were analysed. Writing onset times were measured as the time between the appearance of the stimulus on the screen and the first contact of the pen with the paper. The critical letters (henceforth, L1 and L2) were those located at the morpheme boundary in compounds (TOCA.DISCOS) and the same letters in noncompounds (PESADUMBRE). The two ILIs measured were (a) ILI1, located before the last letter of the first constituent in compounds (TOC_A.DISCOS) and in the same position in noncompounds (PES_ADUMBRE), and (b) ILI2, located in the morpheme boundary in compounds (TOCA_DISCOS) and in the same position in noncompounds (PESA_DUMBRE). Each measure was submitted to a different $t$-test analysis. In the analysis by participants $\left(t_{1}\right)$, means across items for each subject were included in the analysis with the type of word (compound vs noncompound) as a within-subjects variable. In the analysis by items $\left(t_{2}\right)$, means across subjects for each item were included with the type of word as a between-subjects variable. Responses containing misspellings, self-corrections, or those in which a technical error occurred were removed from the analyses (4.61\%; $2.95 \%$ for compounds; $6.25 \%$ for noncompounds). In the analyses conducted on the ILIs, those intervals in which participants did not lift the pen between letters were also disregarded. For ILI1, 8.98\% of the punctuations were removed for this reason overall $(8.59 \%$ for compounds and $9.37 \%$ for noncompounds). For ILI2, $4.06 \%$ of the punctuations were removed (2.66\% for compound words and $5.47 \%$ for noncompounds). Table 1 shows the mean values and standard deviations obtained for writing onset times and for the durations of L1, L2, ILI1, and ILI2 for compounds and noncompounds.

\section{Results and discussion}

A main effect of compoundness was observed only in ILI1, $t_{1}(31)=3.23, p=.003, d=.57 ; t_{2}(35.94)=2.13, p=.040, d=$ .67. This interval was shorter in compounds than in

Table 1 Mean values (in milliseconds) and standard deviations (in parentheses) obtained for writing onset time, writing durations of the two critical letters (LI and L2), and durations of the previous interletters intervals (ILI1, ILI2) for compound and noncompound words in Experiment 1

\begin{tabular}{lll}
\hline Measures (ms) & Compounds & Noncompounds \\
\hline Writing onset time & $1,086(342)$ & $1,088(365)$ \\
L1 & $422(138)$ & $424(144)$ \\
L2 & $318(136)$ & $312(140)$ \\
ILI1 & $89(49)$ & $98(70)$ \\
ILI2 & $126(87)$ & $128(94)$ \\
\hline
\end{tabular}

noncompounds. Remaining effects were not significant (all $t \mathrm{~s}<2$ ). Although compoundness did not affect writing onset time, participants produced a shorter interval when this was the last interval of a word (i.e., the first constituent) than in noncompounds. This finding is in line with the fact that writing durations seem to be shorter at the end of words (Kandel \& Perret, 2015). Participants seem to process the constituents of the compounds as lexemes. These results may be comparable to those obtained by Bertram et al. (2015) in the interval located at the morpheme boundary when typing compound words in response to pictures. However, and as stated by these authors in relation to their results, it is unclear whether this effect was related to late reactivation of the first constituent or to anticipation of the second constituent. In Experiment 2, we manipulated the frequency of the first constituent of the compounds while the frequency of the second constituent and the frequency of the compound were controlled. In Experiment 3 , the frequency of the second constituent was manipulated while keeping constant the frequency of the first constituent and the frequency of the compound. If the effect obtained in ILI1 is related to the access to the first or the second constituent, the duration of this interval should be sensitive to the frequency of the constituent in question.

\section{Experiment 2}

\section{Method}

Participants Thirty-two students ( 22 females), between 18 and 31 years of age ( $M=19$ years and 4 months; $S D=2$ years and 0 months), from introductory courses of the University of $\mathrm{La}$ Laguna, took part in Experiment 2. Before the study, all participants read and signed an informed consent form in accordance with the Declaration of Helsinki. They were native Spanish speakers with no known motor or perceptive disorders. None of them participated in Experiment 1.

Materials Thirty-eight compounds were selected as experimental stimuli. Half of the compounds had a high-frequency first constituent (MEDIA.NOCHE, midnight) and half had a low-frequency first constituent (CASCA.NUECES, nutcracker). Compounds were assigned to the highfrequency (henceforth, HF) condition if their first constituent had a word frequency per million above 75 according to EsPal (Duchon et al., 2013). Compounds with a first constituent with a lexical frequency below 40 were assigned to the lowfrequency (LF) condition. For example, media (half) has a word frequency of 183.72 occurrences per million, whereas casca (cracks) has a word frequency of 0.16 per million. Across conditions, words were matched by the identity of the bigram located at the position corresponding to the morpheme boundary (ILI2). Mean values of whole-word 
frequency, the frequency of the second constituent, mean bigram frequency, ILI1 bigram frequency, orthographic neighbourhood, and word length (number of syllables and letters) were controlled across conditions (all $t \mathrm{~s}<1$ ). The full set of stimuli used in Experiment 2 and mean values of manipulated and controlled variables are shown in Appendix Table 5.

Apparatus, procedure, and statistical analysis Two stimuli were removed from the analyses because an item selected as one of the words included in the high-frequency first constituent condition was a proper noun that had been wrongly identified as a common noun. This word (campofrio) and its counterpart in the low-frequency first constituent condition were removed from the final analyses. The same apparatus, procedure, and dependent variables described in Experiment 1 apply for Experiment 2, and $t$ tests were performed, with the first constituent frequency as a within-subjects variable in the analysis by participants, and as a between-subjects variable in the analysis by items. Following the same exclusion criteria as in Experiment 1, $4.52 \%$ of the punctuations in the writing onset time and letter durations analyses were excluded. For ILI1, participants did not produce an interval in $11.18 \%$ of the observations (10.03\% and $12.33 \%$ in HF and LF, respectively). For ILI2, an overall $7.9 \%$ of punctuations were additionally removed due to the absence of an interval $(7.23 \%$ and $8.55 \%$ for HF and LF, respectively).

\section{Results and discussion}

Mean values and standard deviations for writing onset times and ILI1, ILI2, L1, and L2 durations for compounds with HF and LF first constituents are given in Table 2. The $t$ tests revealed a significant effect of the frequency of the first constituent on writing onset times in the analysis by participants, $t_{1}(31)=3.5, p=.001, d=.62$, that was marginally significant in the analysis by items, $t_{2}(17)=1.56, p=.068, d=.37$. No other differences were significant (all $t \mathrm{~s}<1$ ). ${ }^{1}$

This result supports the idea that access to the orthographic representation of compounds is mediated by the activation of the first constituent, in line with a decomposition account. This finding is also in agreement with previous studies conducted in language comprehension (Duñabeitia, Laka, Perea, \& Carreiras, 2009; Koester, Gunter, \& Wagner, 2007; VergaraMartínez et al., 2009) and with several studies conducted in

\footnotetext{
${ }^{1}$ We thank Jon Andoni Duñabeitia for noticing the undue inclusion of campofrio as a compound word in Experiment 2 and Experiment 3 on earlier drafts. Analyses obtained with the full list of stimuli were similar to those reported here. Constituent frequency significantly affected writing onset times, $t_{1}(31)=3.6, p=.000, d=.64 ; t_{2}(29.21)=1.79, p<.042, d=.58$, and was only marginally significant in the analysis conducted by participants on L1 durations, $t_{1}(31)=1.65, p=.055, d=.029 ; t_{2}<1$. No other differences were significant.
}

Table 2 Mean values (in milliseconds) and standard deviations (in parentheses) obtained for writing onset time, writing durations of the two critical letters (LI and L2), and durations of the previous interletters intervals (ILI1, ILI2) for compound words with high-frequency (HF) first constituents and low-frequency (LF) first constituents in Experiment 2

\begin{tabular}{lll}
\hline Measures (ms) & HF & LF \\
\hline Writing onset time & $1,052(347)$ & $1,105(418)$ \\
L1 & $308(74)$ & $312(74)$ \\
L2 & $270(93)$ & $275(97)$ \\
ILI1 & $70(27)$ & $70(33)$ \\
ILI2 & $91(53)$ & $92(49)$ \\
\hline
\end{tabular}

spoken production (Bien et al., 2005; Koester \& Schiller, 2008). Moreover, it can be integrated within a dual-route model by which a decomposition route is preferred when constituents are previously activated by the context of the task, as proposed by Janssen et al. (2014). According to this idea, and even though they failed to observe a significant effect of the frequency of the constituents in latencies when a typewritten picturenaming task was used, Bertram et al. (2015) predicted that a significant effect of the frequency of the constituents might be found if a copying task was employed. Results from Experiment 2 confirmed this prediction. Moreover, these findings suggest that the retrieval of the first constituent is finished (at the latest) before the interval previous to its last letter (MEDI_A.NOCHE). Neither ILIs nor letters durations were affected by the frequency of the first constituent. This includes ILI1, which showed a significant effect of compoundness in Experiment 1. Also insensitive to the frequency of the first constituent was the duration of ILI2 (the morpheme boundary), where Bertram et al. (2015) observed longer durations in comparison with other ILIs without a morpheme boundary. Thus, results from Experiment 2 do not support the idea that the significant effects obtained in ILI1 in Experiment 1 might be due to the late processing of the first constituent of the compound. However, it is possible that the effect observed in ILI1 duration is related to the anticipation of the second constituent (Bertram et al., 2015). If this is the case, we should find that the frequency of the second constituent modulates the duration of this ILI. Specifically, we predict that this ILI will be shorter for compounds with HF second constituents than for compounds with LF second constituents.

\section{Experiment 3}

\section{Method}

Participants Forty-four students ( 31 females), between 18 and 35 years of age ( $M=19$ years and 3 months; $S D=2$ years and 8 months), from introductory courses of the University of $\mathrm{La}$ 
Laguna, participated in Experiment 3. They were native Spanish speakers with no known motor or perceptive disorders. Before the study, all participants read and signed an informed consent form in accordance with the Declaration of Helsinki. None of them participated in Experiment 1 or Experiment 2.

Materials Forty-six compounds were selected as experimental stimuli. Half of the compounds had a high-frequency second constituent (PISA.PAPELES, paperweight) and half had a low-frequency second constituent (PICA.PEDRERO, stonecutter). Across conditions, words were matched by the identity of the bigram located at the position corresponding to the morpheme boundary (ILI2). In this experiment, it was necessary to select compound words with less contrastive frequency values across conditions than those included in Experiment 2, because of the limited number of potential stimuli available in Spanish. Compounds were assigned to the high-frequency condition if their second constituent had a word frequency above 33 occurrences per million according to EsPal (Duchon et al., 2013), and to the low-frequency condition if the second constituent had a word frequency below 22 occurrences per million. However, the difference between conditions in the frequency of the second component was significant, $t(21)=6.01, p=.000$. Differences between conditions in mean values of whole-word frequency, the frequency of the first constituent, ILI1 bigram frequency, orthographic neighbourhood, and word length (number of syllables and letters) were not significant (all $t \mathrm{~s}<1$ ). The full set of stimuli used in Experiment 3 and mean values of manipulated and controlled variables are shown in Appendix Table 6.

Apparatus, procedure, and statistical analysis The same apparatus, procedure, and statistical analysis described in Experiment 2 were applied to Experiment 3, but with the frequency of the second constituent as a within-subjects variable in the analysis by participants and as a between-subjects variable in the analysis by items. Following the same exclusion criteria as in Experiment 1 and Experiment 2, 2.17\% of the writing onset times and letter durations were excluded from the analyses. An $8.60 \%$ of the punctuations were removed for ILI1 because participants did not produce an interval (7.37\% and $9.83 \%$ in HF and LF, respectively). For ILI2, an overall $8.36 \%$ were removed according to this criterion (6.99\% and $9.73 \%$ for HF and LF, respectively).

\section{Results and discussion}

Mean values and standard deviations obtained in Experiment 3 in writing onset times and ILI1, ILI2, L1, and L2 durations for compounds with $\mathrm{HF}$ and $\mathrm{LF}$ second constituents are shown in Table 3. A main effect of frequency of the second constituent was found in the writing onset times, $t_{1}(45)=7.76$,
Table 3 Mean values (in milliseconds) and standard deviations (in parentheses) obtained for writing onset time, writing durations of the two critical letters (LI and L2), and durations of the previous interletters intervals (ILI1, ILI2) for compound words with high-frequency (HF) second constituents and low-frequency (LF) second constituents in Experiment 3

\begin{tabular}{lll}
\hline Measures (ms) & HF & LF \\
\hline Writing onset time & $1,116(382)$ & $1,267(339)$ \\
L1 & $328(87)$ & $327(83)$ \\
L2 & $277(95)$ & $278(111)$ \\
ILI1 & $77(34)$ & $82(54)$ \\
ILI2 & $110(79)$ & $117(93)$ \\
\hline
\end{tabular}

$p=.000, d=1.14 ; t_{2}(21)=3.02, p=.003, d=0.64$. Responses were initiated faster in compounds with high-frequency second constituents. A significant effect of this variable was also observed in ILI1, $t_{1}(45)=3.26, p=.001, d=0.48 ; t_{2}(21)=$ $1.74, p=.048, d=0.37$. The last ILI within the first constituent was shorter when the second constituent was a highfrequency word. The effect of the constituent frequency in ILI2 reached significance in the analysis conducted by participants, $t_{1}(45)=2.16, p=.018, d=0.32$, but not in the analysis by items, $t_{2}(21)=1.29, p=.105, d=.28 .^{2}$

These results confirm that compounds are initially accessed via their constituents in a copying task. Writing onset times were affected not only by the frequency of the first constituent (Experiment 2), but also by the frequency of the second constituent. This suggests that morphological decomposition takes place before the response has been initiated. Moreover, the effect obtained in ILI1 in Experiment 3 suggests that the effect observed in this position in Experiment 1 is related to the anticipation of the second constituent. When this constituent is of high-frequency, ILI1 is shorter. This pattern of results indicates that the second constituent is not fully planned before the initiation of the written response and that it must be activated (or reactivated) by the end of the production of the first constituent.

\section{General discussion}

Previous research on language comprehension and speech production has usually shown that compounds are accessed via their constituents. However, some authors have reported

\footnotetext{
${ }^{2}$ Analyses obtained with the initial, full list of stimuli (including campofrio and hidrofobia) were largely similar to those reported here. A main effect of frequency of the second constituent was found in the writing onset times, $t_{1}(45)=7.74, p=.000, d=1.14 ; t_{2}(35.9)=3.21, p=.001, d=0.95 . \mathrm{A}$ significant effect was also observed in ILI1, $t_{1}(45)=3.08, p=.002, d=$ $0.45 ; t_{2}(31.44)=1.86, p=.036, d=0.45$. The last ILI within the first constituent was shorter when the second constituent was a high-frequency word. The effect of the constituent frequency in ILI2 reached significance in the analysis conducted by participants, $t_{1}(45)=2.22, p=.016, d=0.33$, but not in the analysis by items, $t_{2}(34.45)=1.33, p=.09$.
} 
evidence supporting that the retrieval of compound words is based only on the compound frequency rather than on the frequency of its constituents in spoken picture naming (Janssen et al., 2008; Janssen et al., 2014) and written picture naming (Bertram et al., 2015). These apparently conflicting results have been integrated within a dual-route model of processing compounds, where a whole-word route is used in the absence of previous context or activation of the constituents (i.e., picture-naming task), and a decomposition route is preferred when constituents are preactivated in some manner by the input (i.e., priming or visual presentation of the stimulus). In the present study, we address this issue for the first time in handwritten compound production by using a copying task.

Results from Experiment 1 revealed that compounds are not produced in the same way that noncompounds are. Namely, the ILI immediately preceding the morpheme boundary (ILI1) in compound words was shorter than the same interval in noncompounds. Experiment 2 and Experiment 3 showed that the frequency of both constituents affected writing onset times. Compound words with high-frequency first and second constituents were initiated faster than were compounds with lowfrequency constituents. Moreover, ILI1 was observed to be shorter for high-frequency second constituents, suggesting that the second constituent is activated before the production of the first constituent has finished. These results confirm the prediction made by Bertram et al. (2015) based on the dual-route procedure of the processing of compound words (Janssen et al., 2014). When a copying task is used, writing onset times seem to be affected by the frequency of both the first and second constituents. Although Bertram and colleagues did not observe a significant effect of the frequency of the constituents in writing onset times in a typewritten picture-naming task, these authors suggested that this effect might be found if a copying task was used. According to these authors, a decomposition route would be activated in any task in which compound words are visually presented (as in the copying task used in the present study), because the input used to trigger the response would transparently contain the compound's constituents. However, in a written picture-naming task, compounds would be retrieved holistically.

Our study cannot by itself confirm or rule out a dualroute account of the production of compounds. Given the scarcity of compound words that can be found in Spanish, it would be extremely difficult to find wellcontrolled materials suitable for a written picturenaming task. Moreover, most of the Spanish compound words have a low frequency of use. Thus, whole-word frequency could hardly be orthogonally manipulated to the frequency of the constituents. Nevertheless, if considered in connection with results reported by Bertram et al.
(2015), the present findings may suggest a dual-route system. Although the dual-route account of compound processing was proposed for spoken production (and there is little evidence supporting that compound words are produced in a similar way in both production modalities), evidence obtained in Bertram et al.'s study and in our study could be easily accommodated by this account. This fact does not preclude that differences between Bertram et al.'s study and our findings might be related to other factors, such as the language used or temporal differences between handwriting and typewriting (see discussion of this issue below). It is also possible that our findings are at least partially due to the low wholeword frequency of the compound words used. The lexical representation of these compounds might be weak, promoting decomposition into their constituents. To clarify this issue, future research directly comparing copying and written picture naming needs to be conducted in a language with a larger number of compounds (e.g., English). In any case, our results are consistent with the idea that Spanish compounds are accessed via their constituents in the copying task.

Writing onset times were affected by the frequency of the first and the second constituent, indicating that both constituents are activated before writing is initiated. Although it would be reasonable to predict that only the first constituent would need to be retrieved to start the response, high-frequency second constituents also affected writing onset times. Both effects were large, but the size of the second constituent frequency effect $\left(\eta_{\mathrm{p}}{ }^{2}=\right.$ .4) was in fact larger than that of the first constituent frequency effect $\left(\eta_{\mathrm{p}}{ }^{2}=.17\right)$. This is not surprising if we consider that Spanish compounds tend to have an ending head (Duñabeitia et al., 2007). This means that the meaning of the second constituent generally has a more direct relation with the meaning of the compound. Thus, the retrieval of the second constituent before writing onset may be especially relevant in languages such as Spanish. More evidence is necessary to determine if both constituents are also activated in languages with an initial head (e.g., French).

These effects obtained in the word onset times are also in line with the results reported in spoken production studies. The frequency of both the first and the second constituent has also been found to affect response latencies in spoken naming tasks (Bien et al., 2005; Juhasz et al., 2003). This might indicate that compounds are similarly processed during written and spoken production. However, caution needs to be taken, given the lack of evidence supporting the idea that both production modalities recruit similar processes. Systematic comparisons between speech and writing production are missing in the literature, but it seems that there is a number of 
effects that cannot be generalised from one modality to the other (Rapp, Benzing, \& Caramazza, 1997; Zhang \& Wang, 2014). Orthographic and phonological representations are quite different in nature, so it is still uncertain if they are processed in equivalent ways. Moreover, producing an orthographic form requires considerably more time than producing a spoken word. This means that in writing research, intervals between sublexical units (such as consecutive letters within a word) can be measured relatively easily, whereas a similar measure in spoken production will be challenging to obtain or too small to be informative. Thus, it is difficult to hypothesise if an effect similar to that found in our study in ILI1 could be observed in spoken production. It may well be the case that compounds are accessed in a similar way in both output modalities, but with writers (but not speakers) needing to reactivate the lexical representation of the second constituent of compounds during production given the length of the utterance. Alternatively, orthographic and phonological representations may be encoded in different ways, although accessed in the lexicon rather similarly. This is certainly a relevant issue warranting future research, but at this point it is not possible to ensure that evidence obtained in writing research can be generalised to our understanding of the spoken production of compound words. In any case, the fact that similar constituent frequency effects has been reported in writing and speech production research might indicate commonalities in the process of accessing compound words in both modalities of language production.

It is worth noting that because to-be-written words were visually presented, it could be argued that the effects obtained in writing onset times could be due to reading rather than to writing processes. However, the fact that the ILIs observed before the last letter of the first constituent in compounds were shorter than those in the same position in noncompounds (ILI1) would be difficult to conciliate with an explanation only in terms of reading processes. Target words would have disappeared a minimum of 2,500 milliseconds before the production of this interval. Thus, this effect is better explained in relation to writing than to reading processes. Moreover, the fact that the duration of this interval was modulated only by the frequency of the second constituent suggests that this effect is related to the anticipation of this constituent and not to a late reactivation of the first constituent. This effect could be related to the effect reported by Bertram et al. (2015) in the morpheme boundary. These authors observed that longer IKIs were produced when the interval represented a morpheme boundary. Although the effect obtained in the present study appeared in the previous interval and in the opposite direction (with shorter durations for compounds than for noncompounds), we think that these differences might be related to the fact that handwriting is slower than typing. Although processing of the second component may occur in ILI2 in typing, there might be time enough for this to occur around ILI1 in handwriting.

Moreover, anticipation of forthcoming units may not be the same in both writing modalities. It is widely accepted in the literature that handwritten production strongly relies on anticipatory processes (Kandel \& Perret, 2014; Maggio, Lété, Chenu, Jisa, \& Fayol, 2012; Orliaguet, Kandel \& Boë, 1997; van Galen, 1991). The influential model of handwriting proposed by van Galen (1991) established that all the hierarchically organised modules involved in handwriting production were active in parallel, with modules higher in the hierarchy being engaged with units further ahead in the response. In a sentence-writing study, Maggio et al. (2015) observed that the processing of a given word started when the previous word was being produced. This result is in line with our finding that the frequency of the second constituent affects the duration of the last ILI of the first constituent. Similarly to the production of consecutive words in a sentence, the second constituent of a compound word seems to be processed while the first component is being written. Whether or not the scope of motor planning in typewriting and handwriting are comparable is an important question that may explain differences observed between studies, and it requires further research. In any case, the results obtained for ILI1 in the present study agree with the concept of anticipation widely accepted in handwriting production research.

Finally, our results confirm that writing durations can be affected by linguistic variables. The influence of central levels of processing on the execution of motor processes during handwriting production it seems to be a pervasive phenomenon largely independent of the characteristics of the task or the writing modality. The fact that the frequency of the second constituent affected writing onset times but also ILI durations, suggests that even processes that have already affected the access to the orthographic representation before the initiation of the response may continue to modulate handwriting movements during production.

In sum, the present study provides evidence of morphological decomposition of compound words in handwritten production. As predicted by dual-route models, constituent frequency effects were observed when a copying task was used. Moreover, the pattern of results obtained suggests that both constituents are activated before writing begins and that the second constituent is accessed again when the production of the first constituent is almost finished.

Acknowledgements This research was partially supported by the Spanish Government (Grant PSI2013-47959-P). We would like to express our gratitude to Alberto Hernández Gómez, Beatriz Pérez de la Portilla, and Anais Martín Jiménez for their helpful collaboration in carrying out the experiments. 


\section{Appendix 1}

Table 4 Experimental stimuli used in Experiment 1. Mean values for controlled variables appear boldfaced

\begin{tabular}{|c|c|c|c|c|c|c|}
\hline Words & WF & NL & NS & $N$ & $\mathrm{MBF}$ & BF_ILI1 \\
\hline \multicolumn{7}{|l|}{ Compounds } \\
\hline Aguamarina & 0.28 & 10 & 5 & 0 & 1,702 & 1,163 \\
\hline Buscavidas & 0.18 & 10 & 4 & 0 & 2,464 & 3,946 \\
\hline Cascanueces & 0.94 & 11 & 4 & 0 & 5,120 & 3,946 \\
\hline Cuentagotas & 0.51 & 11 & 4 & 0 & 7,970 & 6,694 \\
\hline Cumpleaños & 11.07 & 10 & 4 & 0 & 2,757 & 3,038 \\
\hline Entrecejo & 1.33 & 9 & 4 & 0 & 8,883 & 11,800 \\
\hline Gatopardo & 0.19 & 9 & 4 & 0 & 3,229 & 5,321 \\
\hline Guardacostas & 1.74 & 12 & 4 & 0 & 2,172 & 3,472 \\
\hline Hojalata & 1.23 & 8 & 4 & 0 & 2,646 & 1,474 \\
\hline Lavaplatos & 0.19 & 10 & 4 & 0 & 7,662 & 805 \\
\hline Matamoscas & 0.12 & 10 & 4 & 0 & 4,447 & 9,699 \\
\hline Picaporte & 0.86 & 9 & 4 & 0 & 1,931 & 3,500 \\
\hline Sacapuntas & 0.23 & 10 & 4 & 0 & 2,562 & 3,500 \\
\hline Salvavidas & 1.41 & 10 & 4 & 0 & 2,630 & 2,193 \\
\hline Sobrecama & 0.03 & 9 & 4 & 0 & 4,546 & 11,800 \\
\hline Superdotado & 0.64 & 11 & 5 & 1 & 5,696 & 19,630 \\
\hline Tirachinas & 0.35 & 10 & 4 & 0 & 3,445 & 13,969 \\
\hline Tocadiscos & 0.54 & 10 & 4 & 0 & 3,246 & 3,500 \\
\hline Trotamundos & 0.75 & 11 & 4 & 0 & 3,575 & 9,302 \\
\hline Vanagloria & 0.68 & 10 & 4 & 4 & 3,061 & 3,450 \\
\hline Mean & 1.16 & 10 & 4.1 & 0.25 & 3,987 & 6,110 \\
\hline \multicolumn{7}{|l|}{ Noncompounds } \\
\hline Aclamación & 1.28 & 10 & 4 & 1 & 3,186 & 5,426 \\
\hline Esclavista & 1.20 & 10 & 4 & 0 & 4,851 & 4,173 \\
\hline Hermanastra & 0.66 & 11 & 4 & 1 & 5,080 & 5,150 \\
\hline Embriagador & 0.87 & 11 & 4 & 1 & 2,684 & 3,724 \\
\hline Bronceador & 0.04 & 10 & 4 & 1 & 3,593 & 2,275 \\
\hline Impreciso & 1.36 & 9 & 4 & 1 & 4,079 & 11,800 \\
\hline Galopante & 0.66 & 9 & 4 & 0 & 3,437 & 4,338 \\
\hline Complaciente & 2.13 & 12 & 4 & 0 & 7,460 & 2,774 \\
\hline Ramalazo & 0.16 & 8 & 4 & 0 & 3,010 & 4,133 \\
\hline Catapultar & 0.10 & 10 & 4 & 2 & 3,756 & 9,699 \\
\hline Ensamblaje & 1.40 & 10 & 4 & 0 & 5,554 & 4,846 \\
\hline Terapeuta & 1.35 & 9 & 4 & 0 & 5,459 & 13,969 \\
\hline Harapiento & 0.32 & 10 & 4 & 1 & 7,372 & 13,969 \\
\hline Primaveral & 1.88 & 10 & 4 & 1 & 4,716 & 5,150 \\
\hline Secreción & 3.04 & 9 & 3 & 0 & 8,246 & 11,800 \\
\hline Sacerdotisa & 1.29 & 11 & 5 & 0 & 4,640 & 19,630 \\
\hline Intachable & 1.01 & 10 & 4 & 0 & 4,467 & 9,699 \\
\hline Pesadumbre & 1.86 & 10 & 4 & 0 & 4,018 & 4,846 \\
\hline Frotamiento & 0.27 & 11 & 4 & 1 & 3,561 & 9,302 \\
\hline Desagradar & 0.30 & 10 & 4 & 2 & 15,769 & 4,846 \\
\hline Mean & 1.06 & 10 & 4 & 0.6 & 5,247 & 7,577 \\
\hline
\end{tabular}

$\mathrm{WF}=$ word frequency; $\mathrm{NL}=$ number of letters; $\mathrm{NS}=$ number of syllables; $N=$ orthographic neighbourhood; $\mathrm{MBF}=$ mean bigram frequency; $\mathrm{BF} \_\mathrm{ILI} 1=$ positional token frequency of the last bigram of the first constituent of the compound word and same position in the noncompounds (ILI1) 


\section{Appendix 2}

Table 5 Experimental stimuli used in Experiment 2. Mean values for controlled variables appear boldfaced

\begin{tabular}{|c|c|c|c|c|c|c|c|c|}
\hline Words & $1 \mathrm{CF}$ & $2 \mathrm{CF}$ & WF & NL & NS & $N$ & $\mathrm{MBF}$ & BF_ILI1 \\
\hline \multicolumn{9}{|c|}{ HF first constituent } \\
\hline Aguafiestas & 277.37 & 36.20 & 0.20 & 11 & 4 & 0 & 1,600 & 1,163 \\
\hline Aguamarina & 277.37 & 37.29 & 0.28 & 10 & 5 & 0 & 1,702 & 1,163 \\
\hline Bajamar & 106.50 & 258.56 & 0.52 & 7 & 3 & 1 & 2,441 & 1,474 \\
\hline Bocamanga & 86.20 & 24.37 & 0.07 & 9 & 4 & 0 & 1,963 & 3,500 \\
\hline Buenaventura & 201.15 & 13.52 & 4.07 & 12 & 5 & 0 & 6,669 & 2,026 \\
\hline Buscaminas & 75.56 & 30.77 & 0.04 & 10 & 4 & 0 & 2,640 & 3,946 \\
\hline Buscapleitos & 75.56 & 3.74 & 0.04 & 12 & 4 & 0 & 1,721 & 3,946 \\
\hline Buscavidas & 75.56 & 39.14 & 0.18 & 10 & 4 & 0 & 2,464 & 3,946 \\
\hline Campofrío* & 226.68 & 47.74 & 0.81 & 9 & 4 & 0 & 3,636 & 3,094 \\
\hline Camposanto & 226.68 & 94.02 & 0.73 & 10 & 4 & 0 & 5,508 & 3,094 \\
\hline Caradura & 123.97 & 41.15 & 0.28 & 8 & 4 & 4 & 8,510 & 13,969 \\
\hline Entrechocar & $1,895.56$ & 3.89 & 0.13 & 11 & 4 & 1 & 7,205 & 11,800 \\
\hline Medianoche & 183.72 & 273.28 & 9.73 & 10 & 4 & 0 & 3,261 & 3,333 \\
\hline Nochebuena & 273.28 & 201.15 & 1.58 & 10 & 4 & 0 & 2,980 & 586 \\
\hline Parabrisas & $6,823.67$ & 1.38 & 0.95 & 10 & 4 & 0 & 7,331 & 13,969 \\
\hline Paracaídas & $6,823.67$ & 4.79 & 2.51 & 10 & 5 & 0 & 7,374 & 13,969 \\
\hline Pasamano & 103.33 & 234.32 & 0.07 & 8 & 4 & 0 & 7,232 & 4,846 \\
\hline Perroflauta & 69.97 & 7.77 & 0 & 11 & 4 & 0 & 4,157 & 3,857 \\
\hline Siempreviva & 548.28 & 37.13 & 0.13 & 11 & 4 & 0 & 3,102 & 2,068 \\
\hline Mean & 972 & 73 & 1.17 & 9.95 & 4.10 & 0.31 & 4,289 & 5,039 \\
\hline \multicolumn{9}{|c|}{ LF first constituent } \\
\hline Portafolios & 4.99 & 3.74 & 0.40 & 11 & 4 & 0 & 6,197 & 9,302 \\
\hline Quitamiedos & 9.41 & 4.36 & 0 & 11 & 4 & 0 & 8,246 & 9,302 \\
\hline Calamar & 3.21 & 258.56 & 1.20 & 7 & 3 & 1 & 5,887 & 5,426 \\
\hline Tartamudo & 1.87 & 7.29 & 0.43 & 9 & 4 & 1 & 6,409 & 9,302 \\
\hline Compraventa & 39.75 & 70.18 & 2.44 & 11 & 4 & 0 & 8,187 & 11,024 \\
\hline Matamoscas & 23.37 & 8.03 & 0.12 & 10 & 4 & 0 & 4,447 & 9,699 \\
\hline Tragaperras & 1.04 & 0.43 & 0.31 & 11 & 4 & 0 & 2,955 & 2,370 \\
\hline Salvavidas & 9.34 & 39.14 & 1.41 & 10 & 4 & 0 & 2,630 & 2,193 \\
\hline Hidrofobia* & 0.13 & 1.57 & 0.14 & 10 & 4 & 0 & 1,496 & 3,587 \\
\hline Motosierra & 5.65 & 66.91 & 0.23 & 10 & 4 & 0 & 3,529 & 5,321 \\
\hline Tocadiscos & 24.71 & 39.04 & 0.54 & 10 & 4 & 0 & 3,426 & 3,500 \\
\hline Abrecartas & 36.20 & 52.54 & 0.06 & 10 & 4 & 0 & 2,995 & 5,514 \\
\hline Cascanueces & 0.16 & 4.22 & 0.94 & 11 & 4 & 0 & 5,120 & 3,946 \\
\hline Telebasura & 8.72 & 11.50 & 0.16 & 10 & 5 & 0 & 4,083 & 3,422 \\
\hline Limpiabotas & 11.10 & 10.43 & 0.28 & 11 & 4 & 0 & 1,917 & 3,724 \\
\hline Alzacuellos & 17.49 & 2.10 & 0.05 & 11 & 4 & 0 & 2,244 & 507 \\
\hline Ultramar & 3.96 & 258.56 & 4.96 & 8 & 3 & 1 & 3,211 & 5,041 \\
\hline Termofusible & 0.40 & 0.42 & 0 & 12 & 5 & 0 & 3,354 & 1,875 \\
\hline Duermevela & 7.03 & 19.80 & 0.15 & 10 & 4 & 0 & 6,572 & 1,738 \\
\hline Mean & 10.97 & 45.20 & 0.73 & 10.16 & 4.00 & 0.16 & 4,363 & 5,109 \\
\hline
\end{tabular}

*Stimuli removed from the final analyses because of inappropriate selection of the compound word. $1 \mathrm{CF}=$ first constituent frequency; $2 \mathrm{CF}=$ second constituent frequency; $\mathrm{WF}=$ word frequency; $\mathrm{NL}=$ number of letters; $\mathrm{NS}=$ number of syllables; $N=$ orthographic neighbourhood; $\mathrm{MBF}=$ mean bigram frequency; BF_ILI1 = positional token frequency of the last bigram of the first constituent of the compound word and same position in the noncompounds (ILI1); $H F=$ high frequency; $L F=$ low frequency 


\section{Appendix 3}

Table 6 Experimental stimuli used in Experiment 3.Mean values for controlled variables appear boldfaced

\begin{tabular}{|c|c|c|c|c|c|c|c|c|}
\hline Words & $1 \mathrm{CF}$ & $2 \mathrm{CF}$ & WF & NL & NS & $N$ & $\mathrm{MBF}$ & BF_ILI1 \\
\hline \multicolumn{9}{|c|}{ HF second constituent } \\
\hline Abrefácil & 36.20 & 82.11 & 0 & 9 & 4 & 0 & 1,937 & 1,162 \\
\hline Aguamarina & 277.37 & 37.29 & 0.28 & 10 & 5 & 0 & 1,702 & 981 \\
\hline Alzacuellos & 17.49 & 2.10 & 0.12 & 11 & 4 & 0 & 2,251 & 71 \\
\hline Avemaría & 20.63 & 238.82 & 0.27 & 10 & 5 & 0 & 2,656 & 426 \\
\hline Bajamar & 106.50 & 258.56 & 0.52 & 7 & 3 & 1 & 2,441 & 1,474 \\
\hline Bocacalle & 86.20 & 145.95 & 0.30 & 9 & 4 & 0 & 2,613 & 3,500 \\
\hline Boquiabierto & 86.20 & 68.09 & 0.53 & 12 & 4 & 1 & 1,147 & 2,031 \\
\hline Campofrío* & 226.68 & 47.74 & 0.81 & 9 & 4 & 0 & 3,636 & 3,094 \\
\hline Compraventa & 39.75 & 70.18 & 2.44 & 11 & 4 & 0 & 8,187 & 11,024 \\
\hline Cortapapeles & 37.29 & 33.15 & 0.04 & 12 & 5 & 0 & 7,191 & 9,302 \\
\hline Girasol & 47.34 & 146.86 & 2.04 & 7 & 3 & 1 & 4,417 & 13,969 \\
\hline Guardabosques & 21.36 & 33.17 & 0.52 & 13 & 4 & 0 & 1,764 & 3,472 \\
\hline Hidroavión & 0.13 & 48.10 & 0.57 & 10 & 4 & 0 & 5,508 & 3,857 \\
\hline Hierbabuena & 14.99 & 201.15 & 0.33 & 11 & 4 & 0 & 2,641 & 1,761 \\
\hline Medianoche & 183.72 & 273.28 & 9.73 & 10 & 4 & 0 & 3,261 & 3,333 \\
\hline Nochebuena & 273.28 & 201.15 & 1.58 & 10 & 4 & 0 & 2,980 & 586 \\
\hline Paramilitar & $6,823.67$ & 175.71 & 2.34 & 11 & 5 & 0 & 6,250 & 13,969 \\
\hline Pasacalles & 103.33 & 145.95 & 0.35 & 10 & 4 & 0 & 6,825 & 4,846 \\
\hline Pasamano & $6,823.67$ & 234.32 & 0.07 & 8 & 4 & 0 & 7,232 & 4,846 \\
\hline Pisapapeles & 4.91 & 33.15 & 0.21 & 11 & 5 & 0 & 2,117 & 4,846 \\
\hline Portapapeles & 4.99 & 33.15 & 0.08 & 12 & 5 & 1 & 5,258 & 9,302 \\
\hline Perroflauta & 44.91 & 108.26 & 1.09 & 8 & 3 & 0 & 4,604 & 3,857 \\
\hline Salvavidas & 9.34 & 39.14 & 1.41 & 10 & 4 & 0 & 2,630 & 2,193 \\
\hline Mean & 664.78 & 115.54 & 1.11 & 10.04 & 4.13 & 0.17 & 3,880 & 4,517 \\
\hline \multicolumn{9}{|c|}{ LF second constituent } \\
\hline Teléfono & 8.72 & 0.67 & 33.66 & 8 & 4 & 0 & 4,169 & 179 \\
\hline Matamoscas & 23.37 & 8.03 & 0.12 & 10 & 4 & 0 & 4,447 & 9,699 \\
\hline Montacargas & 20.25 & 18.57 & 0.25 & 11 & 4 & 0 & 6,814 & 9,302 \\
\hline Tejemaneje & 0.71 & 0.39 & 0.07 & 10 & 5 & 0 & 1,984 & 1,428 \\
\hline Portamonedas & 4.99 & 22.22 & 0.27 & 12 & 5 & 0 & 5,895 & 9,302 \\
\hline Sacacorchos & 0.19 & 0.18 & 0.41 & 11 & 4 & 0 & 2,254 & 3,500 \\
\hline Puntiagudo & 44.91 & 10.10 & 0.84 & 10 & 4 & 1 & 4,197 & 7,301 \\
\hline Hidrofobia* & 0.13 & 1.57 & 0.14 & 10 & 4 & 0 & 1,496 & 3,857 \\
\hline Buenaventura & 201.15 & 13.52 & 4.07 & 12 & 5 & 0 & 6,669 & 2,026 \\
\hline Cortaplumas & 37.29 & 12.99 & 0.53 & 11 & 4 & 1 & 7,836 & 9,302 \\
\hline Matasuegras & 23.37 & 0.13 & 0.03 & 11 & 4 & 0 & 3,436 & 9,699 \\
\hline Guardabarros & 21.36 & 4.29 & 0.21 & 12 & 4 & 0 & 1,777 & 3,472 \\
\hline Autoafirmación & 26.31 & 20.51 & 0.32 & 14 & 6 & 0 & 1,161 & 5,321 \\
\hline Limpiabotas & 11.10 & 10.43 & 0.28 & 11 & 4 & 0 & 1,917 & 3,724 \\
\hline Cascanueces & 0.16 & 4.22 & 0.94 & 11 & 4 & 0 & 5,120 & 3,946 \\
\hline Telebasura & 8.72 & 11.50 & 0.16 & 10 & 5 & 0 & 4,083 & 3,422 \\
\hline Sacamuelas & 14.51 & 2.14 & 0.11 & 10 & 4 & 0 & 2,124 & 3,500 \\
\hline Parachoques & $6,823.67$ & 3.82 & 0.61 & 11 & 4 & 0 & 6,380 & 13,969 \\
\hline Portamaletas & 4.99 & 4.42 & 0.03 & 12 & 5 & 0 & 6,045 & 9,302 \\
\hline Picapedrero & 4.14 & 0.29 & 0.14 & 11 & 5 & 0 & 1,380 & 3,500 \\
\hline
\end{tabular}


Table 6 (continued)

\begin{tabular}{lllllllll}
\hline Words & $1 \mathrm{CF}$ & $2 \mathrm{CF}$ & WF & NL & NS & N & MBF & BF_ILI1 \\
\hline Pasapurés & 103.33 & 0.07 & 0.02 & 9 & 4 & 0 & 5,486 \\
Tragaperras & 1.04 & 0.43 & 0.31 & 11 & 4 & 0 & 2,846 \\
Lavavajillas & 6.06 & 0.49 & 0.18 & 12 & 5 & 0 & 5,955 \\
Mean & $\mathbf{3 2 1 . 3 2}$ & $\mathbf{6 . 5 6}$ & $\mathbf{1 . 9 0}$ & $\mathbf{1 0 . 8 7}$ & $\mathbf{4 . 3 9}$ & $\mathbf{0 . 0 9}$ & $\mathbf{4 , 0 4 9}$ & $\mathbf{5 , 3 8 1}$ \\
\hline
\end{tabular}

*Stimuli removed from the final analyses because of inappropriate selection of the compound word. $1 \mathrm{CF}=$ first constituent frequency; $2 \mathrm{CF}=$ second constituent frequency; $\mathrm{WF}=$ word frequency; $\mathrm{NL}=$ number of letters; $\mathrm{NS}=$ number of syllables; $N=$ orthographic neighbourhood; $\mathrm{MBF}=$ mean bigram frequency; BF_ILI1 = positional token frequency of the last bigram of the first constituent of the compound word and same position in the noncompounds (ILI1); $H F=$ high frequency; $L F=$ low frequency

\section{References}

Afonso, O., Álvarez, C. J., \& Kandel, S. (2015). Effects of grapheme-tophoneme probability on writing durations. Memory \& Cognition, 43(4). https://doi.org/10.3758/s13421-014-0489-8

Álvarez, C. J., Cottrell, D., \& Afonso, O. (2009). Writing dictated words and picture names: Syllabic boundaries affect execution in Spanish. Applied PsychoLinguistics, 30(2), 205-223. https://doi.org/10.1017/ S0142716409090092

Balota, D. A., Yap, M. J., Cortese, M. J., Hutchison, K. A., Kessler, B., Loftis, B., . . . Treiman, R. (2007). The English Lexicon Project. Behavior Research Methods, 39(3), 445-59.

Bertram, R., Tønnessen, F. E., Strömqvist, S., Hyönä, J., \& Niemi, P. (2015). Cascaded processing in written compound word production. Frontiers in Human Neuroscience, 9, 1-10. https://doi.org/10.3389/ fnhum.2015.00207

Bien, H., Levelt, W. J. M., \& Baayen, R. H. (2005). Frequency effects in compound production. Proceedings of the National Academy of Sciences of the United States of America, 102(49), 17876-81. https://doi.org/10.1073/pnas.0508431102

Caramazza, A., Laudanna, A., \& Romani, C. (1988). Lexical access and inflectional morphology. Cognition, 28(3), 297-332.

Cohen-Goldberg, A. M. (2013). Towards a theory of multimorphemic word production: The heterogeneity of processing hypothesis. Language \& Cognitive Processes, 28(7), 1036-1064. https://doi. org/10.1080/01690965.2012.759241

Delattre, M., Bonin, P., \& Barry, C. (2006). Written spelling to dictation: Sound-to-spelling regularity affects both writing latencies and durations. Journal of Experimental Psychology: Learning, Memory, and Cognition, 32, 1330-1340. https://doi.org/10.1037/0278-7393.32.6. 1330

Dohmes, P., Zwitserlood, P., \& Bölte, J. (2004). The impact of semantic transparency of morphologically complex words on picture naming. Brain and Language, 90(1/3), 203-212. https://doi.org/10.1016/ S0093-934X(03)00433-4

Duchon, A., Perea, M., Sebastián-Gallés, N., Martí, A., \& Carreiras, M. (2013). EsPal: One-stop shopping for Spanish word properties. Behavior Research Methods, 45(4), 1246-1258. https://doi.org/10. 3758/s13428-013-0326-1

Duñabeitia, J. A., Avilés, A., Afonso, O., Scheepers, C., \& Carreiras, M. (2009). Qualitative differences in the representation of abstract versus concrete words: Evidence from the visual-world paradigm. Cognition, 110(2), 284-292. https://doi.org/10.1016/j.cognition. 2008.11.012

Duñabeitia, J. A., Laka, I., Perea, M., \& Carreiras, M. (2009). Is Milkman a superhero like Batman? Constituent morphological priming in compound words. European Journal of Cognitive Psychology, 21(4), 615-640. https://doi.org/10.1080/09541440802079835
Duñabeitia, J. A., Perea, M., \& Carreiras, M. (2007). The role of the frequency of constituents in compound words: Evidence from Basque and Spanish. Psychonomic Bulletin \& Review, 14(6), 1171-1176. https://doi.org/10.3758/BF03193108

Fiorentino, R., \& Poeppel, D. (2007). Compound words and structure in the lexicon. Language \& Cognitive Processes, 22(7), 953-1000. https://doi.org/10.1080/01690960701190215

Guinet, E., \& Kandel, S. (2010). Ductus: A software package for the study of handwriting production. Behavior Research Methods, 42(1), 326-332. https://doi.org/10.3758/BRM.42.1.326

Janssen, N., Bi, Y., \& Caramazza, A. (2008). A tale of two frequencies: Determining the speed of lexical access for Mandarin Chinese and English compounds. Language \& Cognitive Processes, 23, 11911223. https://doi.org/10.1080/01690960802250900

Janssen, N., Pajtas, P. E., \& Caramazza, A. (2014). Task influences on the production and comprehension of compound words. Memory \& Cognition, 42, 780-793. https://doi.org/10.3758/s13421-014-0396-z

Juhasz, B. J., Starr, M. S., Inhoff, A. W., \& Placke, L. (2003). The effects of morphology on the processing of compound words: Evidence from naming, lexical decisions and eye fixations. British Journal of Psychology, 94(2), 223-244. https://doi.org/10.1348/ 000712603321661903

Kandel, S., Alvarez C., \& Vallée, N. (2008). Morphemes also serve as processing units in handwriting production. In M. Baciu (Ed.), Neuropsychology and cognition of language behavioural, neuropsychological and neuroimaging studies of spoken and written language (pp. 87-100). Kerala, India: Research Signpost.

Kandel, S., Peereman, R., \& Ghimenton, A. (2014). How do we code the letters of a word when we have to write it? Investigating double letter representation in French. Acta Psychologica, 148, 56-62. https://doi.org/10.1016/j.actpsy.2014.01.002

Kandel, S., \& Perret, C. (2014). How do movements to produce letters become automatic during writing acquisition? Investigating the development of motor anticipation. International Journal of Behavioral Development, 39(2), 113-120. https://doi.org/10.1177/ 0165025414557532

Kandel, S., \& Perret, C. (2015). How does the interaction between spelling and motor processes build up during writing acquisition? Cognition, 136, 325-336. https://doi.org/10.1016/j.cognition.2014. 11.014

Kandel, S., Spinelli, E., Tremblay, A., Guerassimovitch, H., \& Álvarez, C. J. (2012). Processing prefixes and suffixes in handwriting production. Acta Psychologica, 140(3), 187-195. https://doi.org/10. 1016/j.actpsy.2012.04.005

Koester, D., Gunter, T. C., \& Wagner, S. (2007). The morphosyntactic decomposition and semantic composition of German compound words investigated by ERPs. Brain and Language, 102, 64-79. https://doi.org/10.1016/j.bandl.2006.09.003 
Koester, D., \& Schiller, N. O. (2008). Morphological priming in overt language production: Electrophysiological evidence from Dutch. NeuroImage, 42(4), 1622-1630. https://doi.org/10.1016/j. neuroimage.2008.06.043

Maggio, S., Chenu, F., De Berc, G. B., Pesci, B., Lété, B., Jisa, H., \& Fayol, M. (2015). Producing written noun phrases in French. Written Language \& Literacy, 1, 1-24. https://doi.org/10.1075/wll.18.1. $01 \mathrm{mag}$

Maggio, S., Lété, B., Chenu, F., Jisa, H., \& Fayol, M. (2012). Tracking the mind during writing: Immediacy, delayed, and anticipatory effects on pauses and writing rate. Reading and Writing, 25(9), 21312151. https://doi.org/10.1007/s11145-011-9348-1

Orliaguet, J.-P., Kandel, S., \& Boë, L.-J. (1997). Visual perception of motor anticipation in cursive handwriting: Influence of spatial and movement information on the prediction of forthcoming letters. Perception, 26(7), 905-912. https://doi.org/10.1068/p260905

Pollatsek, A., Hyönä, J., \& Bertram, R. (2000). The role of morphological constituents in reading Finnish compound words. Journal of Experimental Psychology: Human Perception and Performance, 26(2), 820-33.

Rapp, B., Benzing, L., \& Caramazza, A. (1997). The autonomy of lexical orthography. Cognitive Neuropsychology, 14, 71-104. https://doi. org/10.1080/026432997381628
Roux, S., McKeeff, T. J., Grosjacques, G., Afonso, O., \& Kandel, S. (2013). The interaction between central and peripheral processes in handwriting production. Cognition, 127(2), 235-241. https://doi. org/10.1016/j.cognition.2012.12.009

Schreuder, R., \& Baayen, R. H. (1997). How complex simplex words can be. Journal of Memory and Language, 37, 118-139.

van Galen, G. P. (1991). Handwriting: Issues for a psychomotor theory. Human Movement Science, 10(2/3), 165-191. https://doi.org/10. 1016/0167-9457(91)90003-G

Vergara-Martínez, M., Duñabeitia, J. A., Laka, I., \& Carreiras, M. (2009). ERP correlates of inhibitory and facilitative effects of constituent frequency in compound word reading. Brain Research, 1257, 5364. https://doi.org/10.1016/j.brainres.2008.12.040

Zhang, Q., \& Wang, C. (2014). Syllable frequency and word frequency effects in spoken and written word production in a non-alphabetic script. Frontiers in Psychology, 5, 120. https://doi.org/10.3389/ fpsyg.2014.00120

Publisher's note Springer Nature remains neutral with regard to jurisdictional claims in published maps and institutional affiliations. 